\title{
Nutritional Status of Diabetic Mothers and Health of Newborns in Western Algeria
}

\author{
Refka Ouramdane1, Karima Bereksi-Reguig1, Fadl Allah Abou-Bakr², \\ Slimane Belbraouet ${ }^{3}$ \\ ${ }^{1}$ Département de Biologie, Faculté des Sciences de la Nature et de la vie, Université Djilali Liabes, Sidi Bel Abbes, \\ Algérie \\ ${ }^{2}$ Etablissement Hospitalier Spécialisé en Gynécologie Obstétrique, Sidi Bel Abbes, Algérie \\ ${ }^{3}$ Ecole de Nutrition, Université de Moncton, Moncton, Canada \\ Email: bioref@hotmail.fr, slimane.belbraouet@UMoncton.ca
}

Received 12 May 2015; accepted 14 July 2015; published 17 July 2015

Copyright $@ 2015$ by authors and Scientific Research Publishing Inc.

This work is licensed under the Creative Commons Attribution International License (CC BY).

http://creativecommons.org/licenses/by/4.0/

(c) (i) Open Access

\section{Abstract}

The aim of our work is the study of nutrition diabetic women, and the study of the health status of their newborns in West of Algeria. Our study was performed on 165 diabetic mothers aged 20 to 45 years and 161 newborns admitted to the hospital specialized in obstetrics and gynecology of Sidi Bel Abbes. A food survey and anthropometric study were achieved in our population, clinical and socioeconomic data were recorded in an identification card. Our results show that the average age of women with diabetes is $33.26 \pm 5.15$ ans. The socio-economic survey shows that $47.32 \%$ of women have an average monthly income; their education level is low with only $8.06 \%$ having a higher level. Anthropometric parameters show that $\mathbf{4 8 . 0 8 \%}$ of elderly diabetic women aged 30 to 40 years are overweight BMI $>25$. Dietary survey indicates that women experienced iron, calcium and vitamin $B 9$ deficiency. The results of clinical data have shown the existence of gestational di-

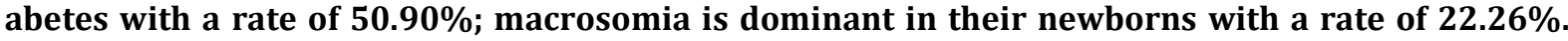
We noted the presence of hypoglycemia in $18.01 \%$ and inutero death in $12.42 \%$.

\section{Keywords}

Nutrition, Diabetic Women, Newborns

\section{Introduction}

In recent decades, diabetes has steadily increased in countries with low and middle incomes. The age at which he declared himself fell a generation to affect individuals of working age and more recently, teens. Therefore, more and more women of childbearing age have diabetes and more pregnancies complicated by diabetes; it is

How to cite this paper: Ouramdane, R., Bereksi-Reguig, K., Abou-Bakr, F.A. and Belbraouet, S. (2015) Nutritional Status of Diabetic Mothers and Health of Newborns in Western Algeria. Food and Nutrition Sciences, 6, 854-859. 
diagnosed before or during pregnancy [1]. Women make an essential contribution to the survival and health of the next generation, and diabetes is a serious problem for women's health [2] [3]. According to [4] gestational diabetes increases the risk of macrosomia (17\% to $29 \%$ against $10 \%$ in the general population). Two studies on the longterm effects of maternal diet in humans have indicated that the ratio of animal protein to carbohydrate may play a significant role in birth weight outcome [5] [6].

The prematurity, hypoglycemia and respiratory distress are still common problems of the newborns [7] [8]. According to [9] [10] eating primarily high glycaemic carbohydrate foods results in foeto-placental overgrowth and excessive maternal weight gain and leads to a predisposition to foetal macrosomia, while the intake of low glycaemic carbohydrate predisposes to normal infant birthweight and normal maternal weight gain. In the USA, the Nurses' Health Study suggested that diabetic women compared with non-diabetic one consumed less energy from carbohydrates, especially from sucrose, and more energy from protein and fat. A longitudinal study including only women indicated that patients do modify their diet as a result of the diagnosis of diabetes [11]. Vitamin $\mathrm{E}$ and $\mathrm{C}$ are both antioxidant vitamins; vitamin $\mathrm{C}$ intakes were lower than the RNI in our diabetics and non-diabetics with a significantly smaller difference for the female diabetics [12].

This work contributes to the study of nutrition of women with diabetes and the state of health of their newborns, to provide information and status of this population to doctors and nutritionists to find a possible solution.

\section{Materials and Methods}

Our study was conducted between July 2011 to June 2013 at the specialist hospital in obstetrics and gynecology of Sidi Bel Abbes, it was performed on 165 pregnant women aged 20 to 45 who have diabetes mellitus with study of the health status of 161 newborns; we took control population of 85 women and 57 newborns who have no pathology. The choice of subjects based on the importance of the study of nutrition in women with diabetes during pregnancy to understand the impact of the illness on the health of her child to contribute to help the doctors to take charge pregnant women and diabetics in particular by the intervention of a nutritionist. To the exclusion criteria were for diabetic women who have other conditions associated with their diabetes.

The anthropometric study involved measuring the weight of the size in mothers and in their newborns. In women, the weight is measured before pregnancy with a person weighs taring the scale before and after each weighed. Infant weight was measured with the aid of an electronic weigh, size is measured with a measuring rod in the mother without shoes and standing, in newborns is measured using a tape measure. In women the body mass index (BMI) is calculated after measuring the weight and size, the ratio of the weight in $\mathrm{kg}$ and height in square expressed in meters. The BMI classification is made according to the World Health Organization (WHO), it is considered normal (BMI 18.5 to 24.9), overweight (BMI 25.0 to 29.9) grade I obesity (BMI 30.0 to 34.9), grade II obesity (BMI 35.0 to 39.9), grade III obesity (BMI > 40.0) [13]. Food survey was conducted using the method of seven day record; the mother interviewed about the quality and quantity of their food starting from breakfast to dinner, the composition of meals is performed using housekeeping measures. Food rations are estimated from usual culinary instruments (spoons, cups, plates...etc.) and the amount was measured using a food scale. Using the program called Nutrilog (Version 1.41) [14], we calculated the nutritional intake of 07 days for each subject the results of the contributions are compared with the RNI [15]. The study was conducted by Statistics SPSS (Version 20), the results were considered significant for $p<0.05$.

\section{Results}

Our study was achieved on 165 diabetic mothers aged 20 to 45 and 161 newborns. The average age of women with diabetes is $33.26 \pm 5.15$ ans, in the control group the mean age was $30.26 \pm 26$. The socio-economic survey of women shows that $29.84 \%$ of these mothers have average level of education. We note that the average monthly income women are the majority (47.32\%) (Table 1$)$. The study clinic in diabetic women showed the existence of gestational diabetes with a high (50.90\%) (Table 2) compared to type I diabetes $(28.49 \%)$ and diabetes type II (20.61\%). The percentage of previous abortions was high among diabetic women (35.76\%), while in the control group abortions were present in only $18.07 \%$ compared with the diabetic women.The rate of deaths in utero prior of $16.97 \%$ in the controls present only $3.61 \%$. The anthropometric study in diabetic mothers has shown that there is a predominant overweight (48.08\%) (BMI 25 to 29.9).The energy, lipid and carbohydrate intakes are higher than in the RNI (recommended dietary allowances). Iron and vitamin B9 is less than the RNI (Table 3). We have noted the existence macrosomia in newborns diabetic mothers with a percentage of 
Table 1. Some socioeconomic parameters in women with diabetes vs control group.

\begin{tabular}{cccc}
\hline & Variable & $\begin{array}{c}\text { Diabetic women (\%) } \\
\mathbf{n = 1 6 5}\end{array}$ & $\begin{array}{c}\text { Control group (\%) } \\
\mathbf{n}=\mathbf{8 5}\end{array}$ \\
\hline Monthly income & High (>27000 dinars) & 15.77 & 18.05 \\
& Medium (<27000 dinars) & 7.32 & 3.2 .20 \\
\multirow{2}{*}{ Education level } & Low (unemployed) & 36.91 & 30.18 \\
& University & 8.06 & 10.11 \\
\hline
\end{tabular}

Table 2. Clinical characteristics and anthropometric parameters in diabetic women vs controls.

\begin{tabular}{ccc}
\hline & Diabetic women (n = 165) & Controls (n = 85) \\
\hline Age & $33 \pm 5.15$ & $30.26 \pm 26$ \\
Type of diabetes & & - \\
Type I & $28.49 \%$ & - \\
Type II & $20.61 \%$ & 0 \\
Gestational diabetes & $50.60 \%$ & 0 \\
Newborns died & $26.06 \%$ & $18.07 \%$ \\
Abortion & $35.76 \%$ & $3.61 \%$ \\
DIU & $16.97 \%$ & \\
BMI & & $10.01 \%$ \\
Overweight $($ BMI $>29.9)$ & $48.08 \%{ }^{*}$ & $8.02 \%$ \\
\hline
\end{tabular}

DIU: Deaths in utero; BMI: Body mass index. ${ }^{*} p<0.05$.

Table 3. Nutritional intake in diabetic and control group compared with RNI.

\begin{tabular}{cccc} 
& $\begin{array}{c}\text { Nutritional intakes of } \\
\text { diabetic women } \\
\mathbf{n}=\mathbf{1 6 5}\end{array}$ & $\begin{array}{c}\text { Control group } \\
\mathbf{n}=\mathbf{8 5}\end{array}$ & RNI \\
\hline Energy (kcal/d) & $2010^{*}$ & 2004 & 2000 \\
Proteins (g/d) & 60 & 59 & 60 \\
Lipids (g/d) & $90^{*}$ & 80 & 66 \\
Carbohydrates (g/d) & $360^{*}$ & 373 & 300 \\
Iron (mg/d) & $4.48^{* *}$ & 3.90 & 600 \\
Vitamin A (ER/d) & 601 & 600 & 110 \\
Vitamin C (mg/d) & 110.5 & 109.5 & 300 \\
\hline Vitamin B9 ( $\mu \mathrm{g} / \mathrm{d})$ & $92.2^{*}$ & 93 & \\
\hline
\end{tabular}

RNI: Recommended nutritional intakes; ER: Equivalent retinol; ${ }^{*} p<0.05 ;{ }^{* *} p<0.01$.

22.36\%, for cons in control it does not exist, hypoglycemia was noted in newborns of diabetic mothers with $18.01 \%$, while in the control does not exist and death in utero in newborns of diabetic mothers is $12.42 \%$ in controls by against is $1.79 \%$ (Table 4 ). The newborns of women with diabetes had a significant weight difference $(p<0.05)$. 
Table 4. Health of newborns of diabetic mothers compared with the control group.

\begin{tabular}{ccc}
\hline & $\begin{array}{c}\text { Newborns of diabetic women } \\
(\mathbf{n}=\mathbf{1 6 1})\end{array}$ & $\begin{array}{c}\text { Newborns of control women } \\
(\mathbf{n}=\mathbf{5 7})\end{array}$ \\
\hline Weight $(\mathrm{kg})$ & $3.67 \pm 0.74^{*}$ & $3.57 \pm 0.44$ \\
Height $(\mathrm{cm})$ & $49.16 \pm 3.67$ & $47.01 \pm 3.89$ \\
Macrosomia & $22.36 \%$ & $0 \%$ \\
Hypoglycemia & $18.01 \%$ & $0 \%$ \\
Intrauterine death & $12.42 \%$ & $1.79 \%$ \\
\hline
\end{tabular}

${ }^{*} p>0.05$.

\section{Discussion}

Our results show that the monthly income of our population means (47.32\%) and the level of education is low for a couple with three children would require an estimated income 27,000 dinars per month afford a balanced diet [16]. The average age of our population is $33.26 \pm 5.15$ years which joined the data retrieved from several authors [17] [18]. The gestational diabetes is high (50.90\%) in pregnancy, there is a particularly clear physiological insulin resistance from the end of the second quarter, which is in particular offset by an increase in the secretion of insulin in the absence of compensation, appears maternal hyperglycemia [19]. Family history of diabetes in the first degree or ethnicity at risk (Asian, African) is frequently found in women. [20]. According to [21] gestational diabetes is diagnosed in 1\% - 3\% of pregnancies and in $17 \%$ of obese women.

The study confirms that abortions and deaths in utero have a higher percentage in women with diabetes compared to healthy women from [22] the vast majority of infant deaths occur during the neonatal period (first month of life), where the risk of death of a child is almost 15 times larger than the first year of life. Nearly 12,000 infants on 350,000 born each day die in the first month of life-the neonatal period-and $98 \%$ of these deaths occur in developing countries. More than four million newborns die each year, and almost as many children are stillborn.

Newborns of diabetic mothers had macrosomia with a rate of $22.36 \%$ as they had hypoglycemia (18.01\%) in agreement with [23] which shows that the frequency of all forms of hypoglycemia between 2.2 and $18 \%$ of admissions of infants, maternal diabetes, whether gestational or pre-existing pregnancy is a known risk factor for fetal macrosomia [24]. Overweight predominant (48.08\%) in diabetic mothers, overweight increases the risk of developing impaired glucose tolerance in the mother [25], the risk of women with gestational diabetes is multiplied by 2 to 6 in an overweight woman according to studies, and up to 20 in obesity [25].

Our study revealed elevated glucose and lipid energy intake in our population which is confirmed by [26], which proves that the diet structure is characterized by a progressive increase in lipid calories of origin. Excessive intake of simple sugars (on empty stomach: snacking) results in a rapid insulin response and increased lipogenesis [27]. After meals, absorption is slower and insulin response is much more gradual. We noted that the intake of iron and vitamin B9 is less than the recommended nutritional intake. The closely spaced pregnancies are physiological situations where the body's iron in the capital does not have time to renew, while further losses or new needs occur [28]. A systematic ferro-folic supplementation is necessary during pregnancy and would be beneficial to the mother and the child [29].

\section{Conclusions}

Our results showed that diabetic women experienced overweight and health problems. They suffered from gestational diabetes, high abortion and death in utero. We note that energy, lipid and carbohydrate intakes are higher than the recommended dietary allowances. In addition, iron and vitamin B9 are less than the recommended dietary allowances resulting in macrosomia and hypoglycemia of newborns.

The health and nutritional status of the mother and her child are closely linked. To improve the health of newborns, we must improve the health and nutritional status of women throughout all stages of life.

\section{Acknowledgements}

The authors thank very much the head doctor and the team specialized in obstetrics and gynecology hospital of 
Sidi Bel Abbes, Algeria.

\section{References}

[1] Fédération internationale du diabète, Atlas du diabète-Quatrième édition (2009) Fédération internationale du diabète, Bruxelles.

[2] Roglic, G. (2009) Diabetes in Women: The Global Perspective. International Journal of Gynecology and Obstetrics, 104, S11-S13. http://dx.doi.org/10.1016/j.ijgo.2008.11.022

[3] Huxley, R., Barzi, F. and Woodward, M. (2006) Excess Risk of Fatal Coronary Heart Disease Associated with Diabetes in Men and Women: Meta-Analysis of 37 Prospective Cohort Studies. BMJ, 332, 73-78. http://dx.doi.org/10.1136/bmj.38678.389583.7C

[4] Brody, S.C., Harris, R. and Lohr, K. (2003) Screening for Gestational Diabetes: A Summary of the Evidence for the U.S. Preventive Services Task Force. Obstetrics \& Gynecology Journal, 101, 380-392. http://dx.doi.org/10.1016/s0029-7844(02)03057-0

[5] Campbell, D.M., Hall, M.H., Barker, D.J.P., Cross, J., Shiell, A.W. and Godfrey, K.M. (1996) Diet in Pregnancy and the Offspring’s Blood Pressure 40 Years Later. British Journal of Obstetrics and Gynaecology, 103, 273-280. http://dx.doi.org/10.1111/j.1471-0528.1996.tb09718.x

[6] Godfrey, K., Robinson, S., Barker, D.J.P., Osmond, C. and Cox, V. (1996) Maternal Nutrition in Early and Late Pregnancy in Relation to Placental and Fetal Growth. British Medical Journal, 312, 401-412. http://dx.doi.org/10.1136/bmj.312.7028.410

[7] Hawthorne, G., Robson, S., Ryall, E.A., Sen, D., Roberts, S.H. and Ward Platt, M.P. (1997) Prospective Population Based Survey of Outcome of Pregnancy in Diabetic Women: Results of the Northern Diabetic Pregnancy Audit, 1994. BMJ, 315, 279-281. http://dx.doi.org/10.1136/bmj.315.7103.279

[8] Reece, E.A. and Homko, C.J. (1994) Infant of the Diabetic Mother. Seminars in Perinatology, 18, 459-469.

[9] Clapp, J.F. (2002) Maternal Carbohydrate Intake and Pregnancy Outcome. Proceedings of the Nutrition Society, 61, 45-50. http://dx.doi.org/10.1079/PNS2001129

[10] Moses, R.G., Luebcke ,M., Davis, W.S., et al. (2006) Effect of a Low-Glycaemic-Index Diet during Pregnancy On obstetric Outcomes. The American Journal of Clinical Nutrition, 84, 807-812.

[11] Shimakawa, T., Herrara-Acena, M.G., Colditz, G.A., Manson, J.E., Stamper, M.J. and Willet, W.C. (1993) Comparison of Diets of Diabetic and Nondiabetic Women. Diabetes Care, 10, 1356-1362. http://dx.doi.org/10.2337/diacare.16.10.1356

[12] Bonnefont-Rousselot, D. (2000) Diabetes and Oxidative Stress. Diabetes Metabolism, 26, 164-176.

[13] OMS and UNICEF (2000) Enquête nationale sur les objectifs de la fin décennie, santé de la mère et de l'enfant. EDG Algérie, 41-65.

[14] Nutrilog Professionnel; Version 1.41.

[15] Potier de Courcy, G., et al. (2003) Besoins nutritionnels et apports conseillés pour la satisfaction de ces besoins. Encyclopédie Médico-Chirurgicale Endocrinologie-Nutrition. Tome 3, Elsevier SAS, Paris, 22.

[16] Khiati, M. (1999) L'essentiel en pédiatrie, Tome 1. Edition ENAL, Alger, 267.

[17] Grosseti, E., Beaucher, G., Regeasse, A., Lamendour, N. and Dreyfs, M. (2004) Complications obstétricales de l’obésité morbide. Journal de Gynécologie Obstétrique et Biologie de la Reproduction, 33, 739-744. http://dx.doi.org/10.1016/S0368-2315(04)96636-7

[18] Matthew, C., Neil, J., John, P., Harris, H. and Stephen, R. (2003) Risk Factors for Macrosomia and Its Clinical Consequences: A Study of 350,311 Pregnancies. European Journal of Obstetrics Gynecology and Reproductive Biology, 111, 9-14. http://dx.doi.org/10.1016/S0301-2115(03)00154-4

[19] Prudhom, C., Jeanmougin, C. and Bastian, D. (2007) Gynécologie obstétrique. Soins infirmiers dans les affections gynécologiques et en maternité, Paris, 192-196.

[20] Berkowitz, G.S., Lapinski, R.H., Wein, R. and Lee, D. (1992) Race/Ethnicity and Other Risk Factors for Gestational Diabetes. American Journal of Epidemiology, 135, 965-973.

[21] Dietl, J. (2005) Maternal Obesity and Complications during Pregnancy. Journal of Perinatal Medicine, 33, 100-105. http://dx.doi.org/10.1515/JPM.2005.018

[22] Yinger, N.V. and Elizabeth, I. (2003) Pourquoi investir dans la santé des nouveau-nés? Perspectives de politique générale sur la santé du nouveau-né, 2-7.

[23] Bhala, A., Willi, R.I., Aldo, P., Bennett, M.J., Schmidt-Sommerfeld, E. and Hale, D.E. (1994) Clinical and Biochemical Characterization of Short-Chain Acyl-Coenzyme: A Dehydrogenase Deficiency. Journal of Pediatrics, 126, 
910-915. http://dx.doi.org/10.1016/S0022-3476(95)70207-5

[24] Carlotti, N., Moquet, P.Y., Foucher, F. and Laurent, M.C. (2000) Le diabète gestationnel: Prise en charge conjointe obstétricale et endocrinienne. Journal de Gynécologie Obstétrique et Biologie de la Reproduction, 4, 403-405.

[25] Galtier-Dereure, F., Boegner-Lemoine, C. and Bringer, J. (2000) Obesity and Pregnancy: Complications and Cost. The American Journal of Clinical Nutrition, 71, 1243S-1248S.

[26] Dekkar, et al. (1999) Un quart de siècle d'études sur la survie de l'enfant algérien 1970-1995. UNICEF-OMS, Alger, 69-178,

[27] Chevalier, B. (1996) Diététique infantile. Masson, Paris, 48-84.

[28] Ramirez-Mateos, C., Loria, A., Nieto-Gomez, M., Malacara, J.M. and Piedras, J. (1998) Anemia and Iron Deficiency in 490 Mexican Pregnant Women. Revista de Investigación Clínica, 50, 119-126.

[29] Dop, M.C., Blot, I., Dyck, J.L., Assimadiw, K., Hodonouq, A.K.S. and Doh, A. (1992) L’anémie à l'accouchement à Lomé (Togo): Prévalence, facteurs de risque et répercussions chez le nouveau-né. Revue d'Epidémiologie et de Santé Publique, 40, 259-267. 